\title{
A review of pediatric femoral fracture patterns, surgical managements, and outcomes
}

\author{
Ahmad K. Almigdad*, Khalid A. Banimelhem, Ghandi K. Almanasir, \\ Ehab M. Altaani, Ala K. Al-Qudah
}

Department of Orthopedic, Royal Medical Services, Jordan

Received: 03 September 2021

Revised: 04 October 2021

Accepted: 06 October 2021

\section{*Correspondence:}

Dr. Ahmad K. Almigdad,

E-mail: akmigdad_just@yahoo.com

Copyright: (C) the author(s), publisher and licensee Medip Academy. This is an open-access article distributed under the terms of the Creative Commons Attribution Non-Commercial License, which permits unrestricted non-commercial use, distribution, and reproduction in any medium, provided the original work is properly cited.

\begin{abstract}
Background: Femoral fractures are the most common pediatric orthopedic fractures that require hospitalization. The non-accidental injury should be suspected in early infancy and non-ambulatory children. Treatment of pediatric femoral fractures is widely variable and depends on intrinsic and extrinsic factors. This study presents pediatric femoral fracture epidemiology and outcomes and reviews the literature regarding best practices in pediatric femoral fractures.

Methods: This retrospective study reviewed the clinical and radiological records of forty-sevens femur fractures in the pediatric age group from September 2020 until June 2021 in Prince Rashid bin AL Hassan Military Hospital in Jordan. Results: Males form $80.9 \%$ of patients. The mean age for the patients was equal to 6.70 years $( \pm 3.91)$. Falling is responsible for the majority of the injury. The middle femur shaft was fractured in $46.8 \%$, and the pathological fracture was found in $17 \%$ of patients. Non-operative treatment by cast represents $42.6 \%$. All fractures were healed at 7.90 weeks $( \pm 2.37)$.

Conclusions: Pediatric femur fracture lacks standardized treatment. Nevertheless, most fractures healed with satisfactory results. Younger age groups are more likely to be treated non-operatively. Non-surgical treatment is more prone to shortening, angulation, and later return to weight-bearing and activity. Children older than eight years treated by plating demonstrated faster healing, return to full weight-bearing, and lower complication rate.
\end{abstract}

Keywords: Femur shat, Fractures, Flexible intramedullary nail, Children, Jordan

\section{INTRODUCTION}

Pediatric femoral fractures are the most common pediatric orthopedic fractures that required hospitalization. ${ }^{1}$ There is a bimodal distribution for pediatric fractures, the first peak between 2-3 years and the second between 16-19 years. ${ }^{2}$

Although the most common etiology for fractures is accidental, child abuse and pathological fracture are important causes. ${ }^{3}$ Non-accidental injuries should be suspected in early infancy, and road traffic accidents are a significant cause in older age groups, especially in developing countries. ${ }^{4,5}$ Unlike adults, the femur shaft is affected more commonly, followed by distal and proximal femur. $^{6}$

Treatment of pediatric femoral fractures is widely variable. It depends on intrinsic factors, including patient age, weight, anatomical site, type of fracture, joint involvement, soft tissue conditions, and associated injuries, in addition to extrinsic factors such as socioeconomic status and physician training. ${ }^{7}$ Treatment modalities include non-operative options like palvic harness and spica casting, while nailing and plating are the most commonly used operative modalities. ${ }^{8}$ 
This study aims to present the epidemiology of pediatric femoral fracture and the outcomes of the used treatment modalities and review the literature regarding best practices in pediatric femoral fractures.

\section{METHODS}

This retrospective study reviewed the clinical and radiological records of forty-sevens femur fractures in the pediatric age group from September 2020 until June 2021. The data were extracted from records of Prince Rashid bin AL Hassan Military Hospital (PRMH), an integrated hospital within the Royal Medical Services hospitals, in Irbid city, north of Jordan.

\section{Data collection}

Patients' data were obtained from patients' records, and their radiographs were evaluated using an archiving system. Fractures were reviewed regarding their patterns, surgical fixation technique, indications, and outcome of the treatment. Pediatric age groups were defined as those ages range from birth to 18 years old.

\section{Statistical data analysis}

The mean and standard deviation were used to describe the continuous variables and the frequencies and percentages for the categorical variables. The variables measured with more than applicable options were described with multiple response dichotomy analysis. The Likelihood Ratio adjusted bivariate chi-square test of independence was used to assess the correlation between categorically measured variables.

The Statistical package for social sciences (SPSS) IBM V21 program was used for the statistical data analysis. The alpha significance level was considered at 0.050 level.

\section{RESULTS}

Forty-seven children with femur fractures were reviewed retrospectively. Table 1 demonstrates the patients' sociodemographic analysis and fractures details. Males form the majority of the sample $(80.9 \%)$, while the remainder $(19.1 \%)$ were females. The mean age for the patients was equal to 6.70 years $( \pm 3.91)$ with an age range (1-16) years. The majority of patients aged between 2-8 years.

The right femur was affected in $59.6 \%$ of cases. All fractures except one are due to falls. The middle femur shaft was the most common site for fractures $(46.8 \%)$, followed by the proximal femur $(27.7 \%)$ and distal femur $(21.3 \%)$ consequently. The femur neck was fractured in two patients $(4.3 \%)$. Regarding fracture morphology, the majority were of spiral and transverse patterns $(38.3 \%$ each). Pathology at fracture site was found in $17 \%$ of patients. Only $10.6 \%$ of fractures were associated with other injuries.
Table 1: Descriptive analysis of patients' demographic features and fractures details.

\begin{tabular}{|c|c|c|}
\hline & Frequency & Percentage \\
\hline \multicolumn{3}{|l|}{ Gender } \\
\hline Female & 9 & 19.1 \\
\hline Male & 38 & 80.9 \\
\hline Age (years), mean (SD) & & $6.70(3.91)$ \\
\hline \multicolumn{3}{|l|}{ Age group (in years) } \\
\hline$\leq 2$ & 4 & 8.5 \\
\hline $2-5$ & 14 & 29.8 \\
\hline $5-8$ & 16 & 34 \\
\hline $8-12$ & 5 & 10.6 \\
\hline$\geq 12$ & 8 & 17 \\
\hline \multicolumn{3}{|l|}{ Affected extremity } \\
\hline Left & 19 & 40.4 \\
\hline Right & 28 & 59.6 \\
\hline \multicolumn{3}{|l|}{ Fracture mechanism } \\
\hline Road traffic accident & 1 & 2.1 \\
\hline Fall & 46 & 97.9 \\
\hline \multicolumn{3}{|c|}{ Anatomical site of the fracture } \\
\hline Distal femur shaft & 10 & 21.3 \\
\hline Femur neck & 2 & 4.3 \\
\hline Middle femur shaft & 22 & 46.8 \\
\hline Proximal femur shaft & 13 & 27.7 \\
\hline \multicolumn{3}{|l|}{ Fracture morphology } \\
\hline Comminated & 4 & 8.5 \\
\hline Oblique & 5 & 10.6 \\
\hline Segmental & 2 & 4.3 \\
\hline Spiral & 18 & 38.3 \\
\hline Transverse & 18 & 38.3 \\
\hline Associated injury & 5 & 10.6 \\
\hline $\begin{array}{l}\text { Patella fracture }+ \text { open } \\
\text { fracture }\end{array}$ & 1 & 20 \\
\hline Pelvic fracture & 2 & 40 \\
\hline $\begin{array}{l}\text { Pneumothorax + open } \\
\text { fracture }\end{array}$ & 1 & 20 \\
\hline Head + chest trauma & 1 & 20 \\
\hline Pathological fracture & 8 & 17 \\
\hline
\end{tabular}

The Table 2 demonstrates the fracture characteristics, treatments, and outcomes. More than half of the fractures were treated surgically, and non-operative treatment by cast represents $42.6 \%$ of cases.

Radiological healing occurs at 7.90 weeks $( \pm 2.37)$. However, $27.7 \%$ of the children had developed shortening of the femur; the mean femoral shortening was equal to 1.81 centimeters $( \pm 0.80)$.

Regarding the angulation in the coronal plane, $21.3 \%$ and $19.1 \%$ had Varus and valgus angulation consequently. The initial Varus angle after reduction was $7.3^{\circ}\left( \pm 1.2^{\circ}\right)$ while at healing, the angle improved to $3.9^{\circ}\left( \pm 1.4^{\circ}\right)$. On the other hand, initial valgus angulation was $9.1^{\circ}\left( \pm 2.2^{\circ}\right)$ which at healing improved to $8^{\circ}\left( \pm 2.7^{\circ}\right)$. 


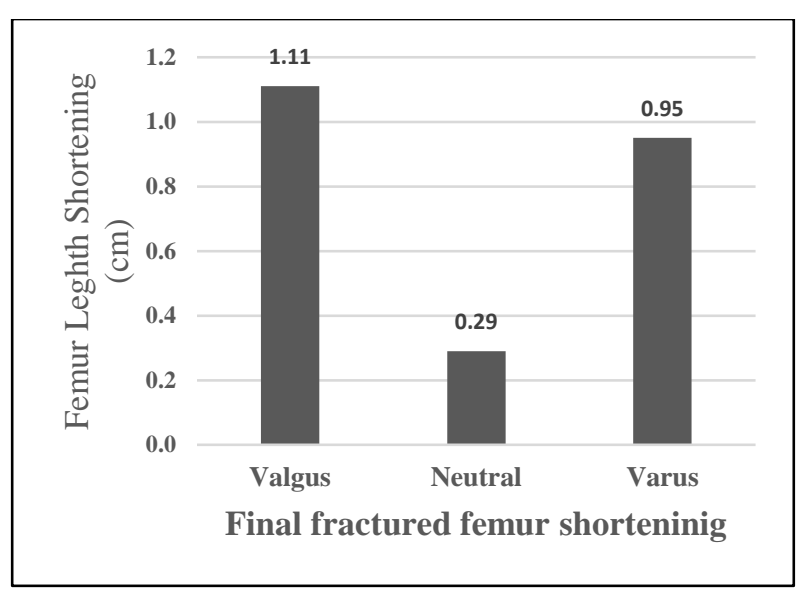

Figure 1: The fractured femur length shortening $(\mathrm{cm})$ with different healed angulation states.

Coronal plane angulation was analyzed according to other variables, Table 3 .

Angulation at the sagittal plane was not measured due to the retrospective design and non-available proper views for measurement. No correlation was detected with patients' gender, affected extremity, anatomical site of the fracture, associated injury, nor the presence of pathology at the fracture site. However, Varus and valgus were more notable at younger age groups, $f(2,22.63)=7.3, p=0.002$, which might be explained by the tendency towards nonoperative treatments in younger age groups which are associated significantly with coronal plane angulation.
Operated femurs were more predicted to neutral position at the coronal plane, $\mathrm{p}=0.011$. Spiral fractures were found to tend varus position while transverse fractures were significantly more predicted to neutral angulation, $\mathrm{p}=0.003$. Angulation at the coronal plane was associated significantly with femur length shortening, see Figure 1.

Table 2: Descriptive analysis of the femur fracture characteristics, treatments, and final outcomes.

\begin{tabular}{|c|c|c|}
\hline Treatment modalities & Frequency & Percentage \\
\hline \multicolumn{3}{|l|}{ Treatment option } \\
\hline Non-operative & 20 & 42.6 \\
\hline Operative & 27 & 57.4 \\
\hline Cast & 20 & 42.6 \\
\hline External fixation & 1 & 2.1 \\
\hline Intramedullary nailing & 13 & 27.7 \\
\hline Plate fixation & 13 & 27.7 \\
\hline \multicolumn{2}{|c|}{$\begin{array}{l}\text { Radiological healing time (weeks), } \\
\text { mean (SD) }\end{array}$} & $7.90(2.37)$ \\
\hline Length shortened? & 13 & 27.7 \\
\hline Length shortening $(\mathrm{cm}), \mathrm{m}$ & nean (SD) & $1.81(0.80)$ \\
\hline \multicolumn{3}{|c|}{ Angulation at coronal plan } \\
\hline Valgus & 9 & 19.1 \\
\hline Neutral & 28 & 59.6 \\
\hline Varus & 10 & 21.3 \\
\hline \multicolumn{2}{|c|}{$\begin{array}{l}\text { The initial angle at the coronal plane } \\
\text { (degrees), mean (SD) }\end{array}$} & $3.34(1.89)$ \\
\hline \multicolumn{2}{|c|}{$\begin{array}{l}\text { The angle at coronal plane at healing } \\
\text { (degrees), mean (SD) }\end{array}$} & $3.10(1.89)$ \\
\hline
\end{tabular}

Table 3: Bivariate analysis of the fractured femur angulation at coronal plane.

\begin{tabular}{|c|c|c|c|c|c|}
\hline & \multicolumn{3}{|c|}{ Femur angulation at coronal plane } & \multirow[b]{2}{*}{ Test statistic } & \multirow[b]{2}{*}{$P$ value } \\
\hline & Valgus & Neutral & Varus & & \\
\hline \multicolumn{6}{|l|}{ Gender } \\
\hline Female & $2(22.2)$ & $5(17.9)$ & $2(20)$ & \multirow{2}{*}{$\chi^{2}(2)=0.10$} & \multirow{2}{*}{0.957} \\
\hline Male & $7(77.8)$ & $23(82.1)$ & $8(80)$ & & \\
\hline Age (years), mean (SD) & $4.67(2.20)$ & $8.28(4.17)$ & $4.10(1.51)$ & $f(2,22.6)=7.30$ & 0.002 \\
\hline \multicolumn{6}{|l|}{ Affected extremity } \\
\hline Left & $5(55.6)$ & $9(32.1)$ & $5(50)$ & \multirow{2}{*}{$\chi 2(2)=2.03$} & \multirow{2}{*}{0.363} \\
\hline Right & $4(44.4)$ & $19(67.9)$ & $5(50)$ & & \\
\hline \multicolumn{6}{|c|}{ Anatomical site of the fracture } \\
\hline Distal femur shaft & $1(11.1)$ & $6(21.4)$ & $3(30)$ & \multirow{4}{*}{$\chi^{2}(6)=3.36$} & \multirow{4}{*}{0.763} \\
\hline Femur neck & 0 & $2(7.1)$ & 0 & & \\
\hline Middle femur shaft & $5(55.6)$ & $13(46.4)$ & $4(40)$ & & \\
\hline Proximal femur shaft & $3(33.3)$ & $7(25)$ & $3(30)$ & & \\
\hline \multicolumn{6}{|l|}{ Fracture morphology } \\
\hline Comminuted & $1(11.1)$ & $3(10.7)$ & 0 & \multirow{5}{*}{$\chi^{2}(8)=23.16$} & \multirow{5}{*}{0.003} \\
\hline Oblique & 0 & $5(17.9)$ & 0 & & \\
\hline Segmental & 0 & $2(7.1)$ & 0 & & \\
\hline Spiral & $7(77.8)$ & $4(14.3)$ & $7(70)$ & & \\
\hline Transverse & $1(11.1)$ & $14(50)$ & $3(30)$ & & \\
\hline \multicolumn{6}{|l|}{ Associated injury } \\
\hline No & $8(88.9)$ & $24(85.7)$ & $10(100)$ & $\chi^{2}(2)=2.6$ & 0.271 \\
\hline
\end{tabular}




\begin{tabular}{|c|c|c|c|c|c|}
\hline & \multicolumn{3}{|c|}{ Femur angulation at coronal plane } & \multirow{2}{*}{ Test statistic } & \multirow{2}{*}{ P value } \\
\hline & Valgus & Neutral & Varus & & \\
\hline Yes & $1(11.1)$ & $4(14.3)$ & 0 & & \\
\hline \multicolumn{6}{|l|}{ Pathological fracture } \\
\hline No & $7(77.8)$ & $22(78.6)$ & $10(100)$ & \multirow{2}{*}{$\chi^{2}(2)=4.30$} & \multirow{2}{*}{0.119} \\
\hline Yes & $2(22.2)$ & $6(21.4)$ & 0 & & \\
\hline \multicolumn{6}{|l|}{ Treatment option } \\
\hline Non-operative & $6(66.7)$ & $7(70)$ & $7(70)$ & \multirow{2}{*}{$\chi^{2}(2)=8.94$} & \multirow{2}{*}{0.011} \\
\hline Operative & $3(33.3)$ & $21(75)$ & $3(30)$ & & \\
\hline \multicolumn{6}{|l|}{ Treatment choice used } \\
\hline Cast & $6(66.7)$ & $7(25)$ & $7(70)$ & \multirow{4}{*}{$\chi^{2}(6)=19.60$} & \multirow{4}{*}{0.003} \\
\hline External fixation & 0 & $1(3.6)$ & 0 & & \\
\hline Intramedullary nailing & $3(33.3)$ & $7(25)$ & $3(30)$ & & \\
\hline Plate fixation & 0 & $13(46.4)$ & 0 & & \\
\hline \multicolumn{6}{|l|}{ Length shortened? } \\
\hline No & $3(33.3)$ & $25(89.3)$ & $6(60)$ & \multirow{2}{*}{$\chi^{2}(2)=11.45$} & \multirow{2}{*}{0.003} \\
\hline Yes & $6(66.7)$ & $3(10.7)$ & $4(40)$ & & \\
\hline Femur length shortening $(\mathrm{cm})$ & $1.11(0.86)$ & $0.29(0.79)$ & $0.95(0.90)$ & $f(2,44)=4.70$ & 0.014 \\
\hline
\end{tabular}

\section{DISCUSSION}

Pediatric femoral fracture treatments vary according to age. Therefore, understanding and adopting evidencebased management protocol improves outcomes. The American Academy of Orthopedic Surgeons (AAOS) introduced a clinical guideline to standardize femur fracture management. ${ }^{9}$ AAOS recommends that suspicion of non-accidental injury should be arisen in children with femoral shaft fracture younger than 36 months, as this reaches $12-14 \% .{ }^{10}$ Non-accidental injuries reach $30 \%$ of non-ambulatory children younger than one year. ${ }^{11}$

Podeszwa et al retrospectively compared Pavlik harness application (24 patients) versus spica casting (16 patients) for the treatment of children under one year of age with a femoral shaft fracture. Podeszwa found no differences in radiographic outcomes between the two groups. Nevertheless, one-third of all spica patients developed a skin complication. Therefore, a Pavlik harness is suitable and safe for children younger than one year. ${ }^{12}$ Similarly, Stannard et al evaluated 16 femur shaft fractures treated with Pavlik harness; all fractures united at five weeks. Secondary to the following advantage of Pavlik harness: ease of application without general anesthesia, minimal hospitalization and cost, ease of reduction, and ability to adjust the harness if the reduction is lost, and ease of nursing, Pavlik harness is recommended in infants' age group. ${ }^{13}$

Most children younger than six years can be treated conservatively by spica casting. Heffernan et al conducted a multicenter retrospective review of 215 patients (141 treated with immediate spica casting, and 74 treated with elastic nails). Although the union time was similar in both groups, the surgically treated group had a shorter time to independent ambulation (Spica $51 \pm 14$ versus Elastic nail
$29 \pm 14$ days) and return to full activities (Spica $87 \pm 19$ versus Elastic nail $74 \pm 28$ days). Additionally, the spica group was found to have a higher rate of leg-length discrepancies and residual deformities, but this was clinically insignificant and did not require treatment. ${ }^{14}$

Leu et al compared double-leg spica casting with singleleg spica casting; all limbs healed in satisfactory alignment with no significant complications. However, a single-leg spica cast allows easier nursing, more comfort, and more easily fit into car seats and chairs. ${ }^{15}$

Sutphen et al compared the radiographic and clinical outcomes of surgically treated pediatric diaphyseal femur fractures in children older than eight years in 198 patients. Fractures treated by flexible intramedullary nailing were associated with an increased incidence of malunion and hardware irritation in addition to longer time to full weight-bearing. Fractures treated by rigid nailing were complicated by an increased risk of limbing, and around one fourth $(23.5 \%)$ had heterotopic ossification. Fractures treated by submuscular plating demonstrated the fastest healing rate (mean, six weeks) and the fastest return to full weight-bearing (mean, seven weeks). Additionally, Submuscular plating showed minimal complication rates. ${ }^{16}$

\section{CONCLUSION}

Pediatric femur fracture lacks standardized treatment. Nevertheless, most fractures healed with satisfactory results. Younger age groups are more likely to be treated non-operatively. Non-surgical treatment is more prone to shortening, angulation, and later return to weight-bearing and activity. Children older than eight years who were treated by plating were demonstrated faster healing, return to full weight-bearing, and lower complication rate. 
Funding: No funding sources

Conflict of interest: None declared

Ethical approval: The study was approved by the institutional ethics committee

\section{REFERENCES}

1. Hedström EM, Svensson O, Bergström U, Michno P. Epidemiology of fractures in children and adolescents. Acta Orthop. 2010;81:148-53.

2. Hedlund R, Lindgren U. The incidence of femoral shaft fractures in children and adolescents. J Pediatr Orthop. 1986;6:47-50.

3. Kamienski MC. Pediatric Femur Fractures. Orthop Nurs. 2020;39(2):107-11.

4. Terra BB, Figueiredo EA, Terra MPEOL, Andreoli CV, Ejnisman B. Child abuse: review of the literature. Rev Bras Ortop. 2013;48(1):11-6.

5. Agarwal-Harding KJ, Meara JG, Greenberg SL, Hagander LE, Zurakowski D, Dyer GS. Estimating the global incidence of femoral fracture from road traffic collisions: a literature review. J Bone Joint Surg Am. 2015;97(6):e31.

6. Talbot C, Davis N, Majid I, Young M, Bouamra O, Lecky FE, Jones S. Fractures of the femoral shaft in children: national epidemiology and treatment trends in England following activation of major trauma networks. Bone Joint J. 2018;100-B(1):109-18.

7. Curran PF, Albright P, Ibrahim JM, Ali SH, Shearer DW, Sabatini CS. Practice Patterns for Management of Pediatric Femur Fractures in Low- and MiddleIncome Countries. J Pediatr Orthop. 2020;40(5):2518.

8. Maier M, Maier-Heidkamp P, Lehnert M, Wirbel R, Marzi I. Ausheilungsergebnisse konservativ und operativ versorgter kindlicher Femurfrakturen [Results of femoral shaft fractures in childhood in relation to different treatment modalities]. Unfallchirurg. 2003;106(1):48-54.

9. Jevsevar DS, Shea KG, Murray JN. AAOS clinical practice guideline on the treatment of pediatric diaphyseal femur fractures. J Am Acad Orthop Surg 2015;23(12):e101.

10. Rewers A, Hedegaard H, Lezotte D. Childhood femur fractures, associated injuries, and sociodemographic risk factors: a population-based study. Pediatrics 2005;115(5):e543-52.

11. Sink EL, Hyman JE, Matheny T,. Child abuse: the role of the orthopaedic surgeon in non-accidental trauma. Clin Orthop Relat Res. 2011;469(3):790-7.

12. Podeszwa DA, Mooney JF 3rd, Cramer KE, Mendelow MJ. Comparison of Pavlik harness application and immediate spica casting for femur fractures in infants. J Pediatr Orthop. 2004;24(5):460-2.

13. Stannard JP, Christensen KP, Wilkins KE. Femur fractures in infants: a new therapeutic approach. J Pediatr Orthop. 1995;15(4):461-6.

14. Heffernan MJ, Gordon JE, Sabatini CS, Keeler KA, Lehmann CL, O'Donnell JC, et al. treatment of femur fractures in young children: a multicenter comparison of flexible intramedullary nails to spica casting in young children aged 2 to 6 years. J Pediatr Orthop. 2015;35(2):126-9.

15. Leu D, Sargent MC, Ain MC, Leet AI, Tis JE, Sponseller PD. Spica casting for pediatric femoral fractures: a prospective, randomized controlled study of single-leg versus double-leg spica casts. J Bone Joint Surg Am. 2012;94(14):1259-64.

16. Sutphen SA, Mendoza JD, Mundy AC, Yang JG, Beebe AC, Samora WP 3rd et al. Pediatric Diaphyseal Femur Fractures: Submuscular Plating Compared With Intramedullary Nailing. Orthopedics. 2016;39(6):353-8.

Cite this article as: Almigdad AK, Banimelhem KA, Almanasir GK, Altaani EM, Al-Qudah AK. A review of pediatric femoral fracture patterns, surgical managements, and outcomes. Int J Res Orthop 2021;7:1080-4. 